\title{
Pharmacy Clarification of Prescriptions Ordered in Primary Care: A Report from the Applied Strategies for Improving Patient Safety (ASIPS) Collaborative
}

\author{
Laura B. Hansen, PharmD, Douglas Fernald, MA, Rodrigo Araya-Guerra, \\ John M. Westfall, MD, MPH David West, PhD, and Wilson Pace, MD
}

Introduction: Prescription errors threaten patient safety and pharmacists often contact providers for prescription clarification. This study describes the principal reasons pharmacies call primary care practices to clarify prescriptions and subsequent implications for quality and patient safety improvement.

Methods: A cross-sectional study of 22 primary care practices participating in a patient safety study was performed. Callbacks from pharmacies were logged for 2 weeks to determine reasons for callbacks, most frequently involved drug classes, whether issues were resolved on the same day of the call, and variability of callbacks among practice types. Analyses were performed using frequencies, $t$ tests, and $\chi^{2}$ tests.

Results: Practices recorded 567 clarification calls, most frequently for prior authorization issues $(n=209 ; 37 \%)$, formulary issues $(n=148 ; 26 \%)$, and unclear/missing prescription dosages $(n=117$; $21 \%)$. Drug classes most frequently requiring clarifications were gastrointestinal $(n=122 ; 21.7 \%)$, cardiovascular $(n=278 ; 13.9 \%)$, and analgesic/anesthetic $(n=74 ; 13.2 \%)$ agents. Issues were resolved on the same day $62 \%$ of the time. Residency practices averaged more issues per call $(P<.001)$.

Conclusions: Clarification calls made to primary care practices involve administrative and clinical issues, potentially impacting patient safety. Pharmacy callback data can identify potential prescription concerns, thereby helping practices develop interventions aimed at reducing errors and improving patient safety. (J Am Board Fam Med 2006;19:24-30.)

Medication errors have been well studied in inpatient settings and represent a significant threat to patient safety. ${ }^{1-7}$ In one study, $6.5 \%$ of hospitalized patients had an adverse drug event, and $28 \%$ of these events were considered preventable. ${ }^{1}$ In hospitals and skilled nursing facilities, $19 \%$ of medication doses were in error. ${ }^{2}$ Extrapolation from previous studies indicate that nationally at least 91,000 patients each year suffer harm by medication errors in general hospitals. ${ }^{3}$ Furthermore, medical errors

Submitted 19 January 2005; revised 25 July 2005; accepted 1 August 2005.

From the Departments of Clinical Pharmacy $(\mathrm{LBH})$ and Family Medicine (LBH, DF, RA-G, JMW, DW, WP), University of Colorado Health Sciences Center, Denver, CO.

Funding: Grant support was received from the Agency for Healthcare Research and Quality (U18 HS11878).

Conflict of interest: none declared.

Previous presentation of work: Fernald D, Araya-Guerra R, Hansen L, West D, Westfall J, Pace W. Pharmacy clarification of prescriptions ordered in primary care: a report from the ASIPS collaborative. North American Primary Care Research Group, 2003 Annual Meeting, Banff, Alberta, Canada.

Corresponding author: Laura B. Hansen, PharmD, University of Colorado Health Sciences Center, School of Pharmacy, 4200 East 9th Avenue, Box C238, Denver, CO 80262 (E-mail: laura.hansen@uchsc.edu). that could be prevented result in total costs of between $\$ 17$ billion and $\$ 29$ billion per year in hospitals nationwide. ${ }^{4}$

In the outpatient setting, errors in prescribing represent a similar, but under-investigated threat to safety. ${ }^{8,9}$ Providers have been encouraged to implement safety systems to ensure safe practices at the level where most patient care takes place. ${ }^{4}$ However, providers may not be aware of the types of prescription problems that require clarification nor the types of medications most likely to require a pharmacist callback. Incorrect prescribing can lead to delays in dispensing or to the patient receiving the wrong medication. A delay or a mistake could compromise patient safety. To our knowledge, there is no literature that discusses the primary reasons pharmacists contact primary care clinics to clarify prescription orders. The goal of this study was to identify sources and patterns of prescribing problems that are amenable to changes designed to prevent future occurrences of error. The main outcome measures were reasons for pharmacy callbacks, drug classes most frequently recorded for callbacks, whether issues were resolved on the same day of the call, and variability among practice types. 


\section{Methods}

Applied Strategies for Improving Patient Safety (ASIPS) was a demonstration project that collected and analyzed medical error reports from clinicians and staff in 34 primary care practices within 2 practice-based research networks (PBRNs), the Colorado Research Network (CaReNet) and the High Plains Research Network (HPRN) from 2001 to 2004 . Urban, rural and residency-based practices were included in the networks. ASIPS was established to understand significant issues concerning patient safety in primary care settings. The voluntary error reporting system received a significant number of reports related to medication errors (prescribing, dispensing, and monitoring). From over 800 events that were submitted to the reporting system, approximately $25 \%$ percent involved medication. Reports have identified errors occurring throughout the prescription process, including errors both in writing prescriptions and in dispensing prescriptions. Pharmacists often intervened with phone calls to the clinics to clarify prescriptions. This study describes the principal reasons for pharmacy callbacks in primary care practices and the implications for patient safety improvement.

\section{Design and Sample}

This was a cross-sectional study of 22 primary care practices within ASIPS. Participating sites were selected from among those already participating in the larger ASIPS study. A total of 27 of the 34 ASIPS practices were invited to participate; 23 agreed to participate and 22 practices completed the study. Seven sites were not invited to participate because of concurrent ASIPS studies occurring in those practices. Although having agreed to participate, one practice failed to complete the necessary documentation and return it in a timely manner. The sample of 22 sites included 7 residency programs, 9 rural or community health centers (CHC), and 6 urban/suburban practices. One practice used an electronic medical record (EMR) with electronic prescribing; all other sites used paper charting and prescribing at the time of the study. Institutional review board approval was granted by the institutions of all participating sites before data collection. Each practice collected data for a 2-week period between October 2002 and June 2003. The sampling time frame was determined by individual practices' ability to participate in the study.

\section{Data Collection and Analysis}

A daily tracking form was created to capture calls received at the practices from pharmacies (Table 1). In each participating practice, nursing or administrative staff used the tracking form to record callbacks, indicating the name of the drug or device, the reason or reasons the pharmacy called to clarify the prescription, and if the issue was resolved on the same day of the call. The data collectors could select any combination of 9 reasons for the pharmacy calls: medication not on formulary, prior authorization issues, illegibility, sig (instructions), amount, type (route), dosage, refill, or "other." Data were also collected from each site about the number of prescribing clinicians, based on full time employent (FTE), and the average number of daily patient visits.

After the data were collected, a clinical pharmacist confirmed drug or device names and substituted generic drug names for all trade name entries. The drugs were then categorized into drug classes based on therapeutic category using Medispan's Therapeutic Classification System (GPI codes), a hierarchical system of classifying pharmaceutical products. ${ }^{10}$ The clinical pharmacist was blinded to all identifiers of practice type or site. Medications were determined to be "acute" when the medical condition could worsen or cause prolonged pain because of a delay in therapy, such as antibiotics or analgesics.

Overall frequencies were calculated for individual drugs, drug classes, reasons for calls, and whether the issues were resolved on the same day as the call. Frequencies of daily callback rates by practice type and by number of FTE prescribing clinicians at each practice were calculated and $t$ tests were performed comparing callback rates in residency practices to other practices. $\chi^{2}$ tests were performed to compare residency practices with others based on the number of issues per call.

\section{Results}

Among the 22 sites, a total of 567 calls from pharmacies were recorded with 354 calls made to residency practices, 109 calls to urban practices, and 104 calls to rural practices. Combined, there were 220 site-days during the study period (10 working days per site per $\log \times 22$ sites). Average callback rates were 2.6 calls per day (567 calls/220 days). The total number of callbacks recorded by all sites 
Table 1. Daily Tracking Form to Record Pharmacy Callbacks*

Medication Clarification Log

Select a type of practice (check one): $\square$ Community Health Center $\square$ Residency Practice (even if also CHC) $\square$ Rural Office $\square$ Non-residency, Urban/Suburban Office

Make an $\mathbf{X}$ in the column indicating the reason for the inquiry (check all that apply)

\begin{tabular}{l|l|l|l|l|l|l|l|l} 
Issue Resolved \\
Same Day as \\
Drug \\
Name ILLEGIBLE TYPE DOSAGE SIG AMT REFILLS AUTH FORMULARY OTHER \\
Inquiry Received \\
(mark X if yes)
\end{tabular}

Definitions: ILLEGIBLE, prescription illegible (eg, pharmacy unable to read the prescription as written; TYPE, wrong or unspecified type (eg, ointment versus cream, tablets versus liquid); DOSAGE, wrong or unspecified dosage (eg, doesn't come in ordered strength, unusually high or low dosage); SIG, wrong or unspecified directions (eg, no directions, directions don't match amount prescribed); AMT, wrong or unspecified amount (eg, no amount listed, amount doesn't match instructions); REFILLS, wrong or unspecified refills (eg, number of refills not documented); PRIOR AUTH, clarify a prior authorization (eg, authorized by insurance company); NOT IN FORMULARY, specified drug not in formulary; OTHER, anything that doesn't fit in above categories.

* Instructions: Please use this log for 2 weeks for any medication clarification inquiries. During the 2-week period, please log each prescription inquiry and the type of clarification. Please mail the completed logs in the postage-paid envelope. To complete the log, please:

1. Use a separate sheet for each day of the week. If there are no inquiries, make a large $\varnothing$ or write NONE in the middle.

2. Indicate the name of the drug (generic or trade).

3. Indicate the nature of the clarification; indicate all reasons for the inquiry by marking an $\mathbf{X}$ in the box or boxes (see Definitions).

4. Indicate whether the issue was resolved on the same day as the inquiry was received. If you were able to resolve the issue on the same day, mark an $\mathbf{X}$ in the box; if not resolved, leave the box empty.

ranged from 0 to 161 , with a range of 8 to 161 (mean \pm SD: $50.6 \pm 55.5$ ) for residency practices, 4 to 69 (mean \pm SD: $18.7 \pm 25.2$ ) in urban/ suburban practices, and 0 to 37 (mean \pm SD: $11.6 \pm 12.8)$ in rural practices.

\section{Reasons for Callbacks}

Among the 9 categories of reasons for callbacks, the most frequent reasons were prior authorization $(\mathrm{n}=209 ; 37 \%)$, formulary issues $(\mathrm{n}=148 ; 26 \%)$, and unclear or missing dosages $(\mathrm{n}=117 ; 21 \%)$. For clarity, reasons for callback were separated into administrative and clinical categories. Administrative reasons included any issue in which the prescription required clarification for insurance or pharmacy reasons (eg, prior authorization, formulary, refills), and all other issues were considered clinical reasons (eg, dosage, instructions, amount). Table 2 details the frequency of each problem involved in the calls.

\section{Drug Classes}

The sites recorded callbacks involving 192 unique drugs in 13 broad drug classes (Table 3). The most 
Table 2. Types of Clarification Needed in Pharmacy Callbacks

\begin{tabular}{lc}
\hline Clarification Type & $\begin{array}{c}\text { Number of Calls } \\
\text { (Percentage of All Calls) }^{*}\end{array}$ \\
\hline Administrative & \\
Prior authorization & $209(37)$ \\
Formulary & $148(26)$ \\
Other & $94(17)$ \\
Refills $\dagger$ & $62(11)$ \\
Total & $394(69)$ \\
Clinical & \\
Dosage & $117(21)$ \\
Sig (instructions) & $54(10)$ \\
Amount & $32(6)$ \\
Type (route) & $17(3)$ \\
Illegible & $11(2)$ \\
Total & $191(34)$ \\
\hline
\end{tabular}

* Combined totals of administrative and clinical reasons for callbacks are greater than $100 \%$ because each call could involve multiple types of clarification.

† Wrong or unspecified refills (eg, number of refills not documented).

frequent drug classes recorded in the pharmacy callback forms were gastrointestinal agents $(\mathrm{n}=$ $122 ; 21.5 \%)$, cardiovascular agents $(\mathrm{n}=79$; $13.9 \%$ ), and analgesics and anesthetics ( $\mathrm{n}=74$; $13.1 \%)$. The most frequent medications recorded in the pharmacy callback forms were lansoprazole $(\mathrm{n}=63 ; 11.1 \%)$, omeprazole $(\mathrm{n}=24 ; 4.2 \%)$ and levothyroxine $(\mathrm{n}=17 ; 3.0 \%)$. The most frequent reasons for callbacks within drug classes are provided in Table 4. Although administrative problems appeared in many calls, clinical issues, such as

Table 3. Drug Classes Most Frequently Recorded for Pharmacy Callbacks

\begin{tabular}{lr}
\hline Broad Drug Class & $\mathrm{n}(\%)$ \\
\hline Gastrointestinal agents & $122(21.5)$ \\
Cardiovascular agents & $79(13.9)$ \\
Analgesics and anesthetics & $74(13.1)$ \\
Respiratory agents & $71(12.5)$ \\
Central nervous system drugs & $71(12.5)$ \\
Endocrine and metabolic drugs & $60(10.6)$ \\
Anti-infective agents & $31(5.5)$ \\
Topical products & $16(2.8)$ \\
Genitourinary products & $16(2.8)$ \\
Neuromuscular drugs & $12(2.1)$ \\
Miscellaneous products & $7(1.2)$ \\
Nutritional products & $6(1.1)$ \\
Hematological agents & $1(0.2)$ \\
Unable to classify (drug not recorded) & $1(0.2)$ \\
Total & $567(100)$ \\
\hline
\end{tabular}

Table 4. Top Reasons for Callback by Drug Class

\begin{tabular}{|c|c|c|}
\hline $\begin{array}{l}\text { Reason for Callback } \\
\text { (no. of calls) }\end{array}$ & $\begin{array}{l}\text { Most Common } \\
\text { Drugs }\end{array}$ & $\begin{array}{l}\text { Percentage of Calls } \\
\text { (n drug/n reason) }\end{array}$ \\
\hline $\begin{array}{l}\text { Prior authorization } \\
\text { (209) }\end{array}$ & $\begin{array}{l}\text { Ulcer drugs } \\
\text { Analgesics, narcotics } \\
\text { Antiasthmatic }\end{array}$ & $\begin{array}{r}43.5 \\
6.2 \\
5.7\end{array}$ \\
\hline Formulary (146) & $\begin{array}{l}\text { Ulcer drugs } \\
\text { Analgesics, narcotics } \\
\text { Antirheumatic }\end{array}$ & $\begin{array}{r}37.8 \\
5.4 \\
5.4\end{array}$ \\
\hline Dosage (117) & $\begin{array}{l}\text { Antidepressants } \\
\text { Thyroid } \\
\text { Analgesics, narcotics }\end{array}$ & $\begin{array}{r}13.7 \\
9.4 \\
8.5\end{array}$ \\
\hline Other (93) & $\begin{array}{l}\text { Antiasthmatic } \\
\text { Analgesics, narcotics } \\
\text { Ulcer drugs }\end{array}$ & $\begin{array}{r}10.6 \\
8.5 \\
7.4\end{array}$ \\
\hline Refills (62) & $\begin{array}{l}\text { Analgesics, narcotics } \\
\text { Thyroid } \\
\text { Ulcer drugs }\end{array}$ & $\begin{array}{r}14.5 \\
9.7 \\
8.1\end{array}$ \\
\hline Sig* (53) & $\begin{array}{l}\text { Ulcer drugs } \\
\text { Antidiabetic } \\
\text { Thyroid }\end{array}$ & $\begin{array}{r}13.0 \\
9.3 \\
7.4\end{array}$ \\
\hline Amount (32) & $\begin{array}{l}\text { Thyroid } \\
\text { Analgesics, narcotics } \\
\text { Antidiabetic }\end{array}$ & $\begin{array}{r}12.5 \\
9.4 \\
9.4\end{array}$ \\
\hline Type (14) & $\begin{array}{l}\text { Dermatological } \\
\text { Antidepressants } \\
\text { Systemic and topical } \\
\text { nasal products }\end{array}$ & $\begin{array}{l}17.6 \\
11.8 \\
11.8\end{array}$ \\
\hline Illegible (10) & $\begin{array}{l}\text { Ulcer drugs } \\
\text { Penicillins } \\
\text { Antihypertensive }\end{array}$ & $\begin{array}{r}18.2 \\
18.2 \\
9.1\end{array}$ \\
\hline
\end{tabular}

* Sig, directions.

illegibility and specifying formulations, were noteworthy sources of ambiguity for written prescriptions among the sample of practices.

\section{Residency Practices}

Residency practices in our sample had callback rates per FTE clinician that were not significantly different from other participating practices $(0.58$ calls/residency clinician vs. 0.55 calls per other clinician, $P>$.9). However, the number of reasons per call (ie, per prescription) was significantly higher among residency practices. Calls having 2 or more reasons for clarification represented $41 \%$ $(145 / 567)$ of calls to residency practices and only $6 \%(13 / 567)$ of the calls to other types of practice $(P<.001)$.

\section{Delay in Dispensing}

As an estimated indicator of delay in dispensing, it was determined whether the problems related to each prescription were resolved on the same day as the call. Records indicated that $62.0 \%$ of the problems were resolved on the same day. Those cases 
with at least one administrative reason for callback were resolved the same day $58.0 \%$ of the time, whereas clinical callbacks were resolved $69.4 \%$ of the time $(P=.011 ; 18$ cases with both types of reasons were excluded from the $\chi^{2}$ calculations). However, the problem was not resolved on the same day $34 \%$ of the time when an "acute" medication was in question. For example, issues regarding antibacterials were not resolved within one day for 6 of 21 calls (28.6\%), antifungals for 3 of 9 calls (33.3\%), and narcotics for 16 of 43 calls $(37.2 \%)$. Medications needed for genital herpes were not resolved for 2 of 2 calls (100\%), constipation for 2 of 2 calls $(100 \%)$ and for migraine 2 of 3 calls (66.7\%).

\section{Discussion}

Our study clearly indicates that callbacks from pharmacies are common in primary care practices and prescriptions commonly have multiple issues that need to be addressed. Rural practices may have lower callback rates because of fewer clinicians, less managed care influence, and agreements between physicians and pharmacists about making prescription clarifications. In addition, rural pharmacists may be more familiar with the prescribing patterns of the relatively small number of clinicians, handle fewer prescriptions on a daily basis and be the only pharmacist (or pharmacy) involved in patients' care. Calls related to administrative issues, specifically formulary and prior authorizations, represent a potential patient safety concern with delayed therapy or compliance errors because of changes in dosage or frequency. These issues may also be a significant source of ambiguity for clinicians with frequent formulary changes.

It was not surprising that the most common reasons for callbacks of antiulcer/dyspepsia agents were regarding prior authorization and formulary issues as there are many options, and companies frequently negotiate prices with insurance carriers. Problems associated with prior authorization and formulary issues could potentially be minimized within primary care practices if electronic prescribing systems can be installed with accurate formularies. In addition, to decrease delays in treatment, it is important for insurers to provide up to date information to providers. Automatic substitution within a class of medication (eg, omeprazole for lansoprazole or lisinopril for fosinopril) may also ease the burden on busy providers who are unable to keep up with evolving formularies.

More importantly, our study identified threats in patient safety with various clinical reasons for callbacks that led to delays in dispensing of acute medications, and ambiguities in dosage, instructions, type, amount, and illegibility. Although low in number, acute medication prescription problems were not resolved on the same day $34 \%$ of the time. This has potentially significant consequences for patients who experience delays in therapy that could have a serious impact on the timely treatment of illnesses and patient quality of life.

Regarding dosage, prescriptions for thyroid agents were commonly clarified. This is clinically important because a narrow therapeutic window exists, and inappropriate dosing could lead to significant patient side effects and adverse outcomes. Similarly, incorrect dosing of antihypertensive medications could lead to inappropriate control of blood pressure and significant life-threatening outcomes, such as heart attack, stroke or falls. These types of callbacks point to interventions that are largely within the control of practices, their clinicians and staff. Such interventions may involve innovations in information technology. Again, point of entry systems that ensure appropriate prescribing and legibility improve patient safety concerns that exist within the outpatient setting. ${ }^{11-13}$ Unfortunately, because just one practice was using electronic prescribing through an EMR there were too few data in our study for meaningful comparative analysis.

Regarding prescription clarification, it has not been previously demonstrated that there may be a difference between residency practices and other types of primary care environments. Our results indicated that there was no difference in the number of phone calls received per provider, but that there were a significantly higher number of reasons for each clarification call made to residency practices. This phenomenon may be addressed with more extensive training for prescription writing and more careful examination of patient records to determine appropriate therapeutic regimens.

There were several limitations to this study. First, the practices that were included in the study volunteered to record data and complete the necessary information. Although most invited practices (22/27) within ASIPS participated, several practices did not participate and selection bias may have 
occurred. With an $81.5 \%$ response rate, this likelihood is small. Research in PBRNs generally is considered to improve generalizability because the inquiries are performed across a range of practice locations and types. ${ }^{14}$ Second, practices determined when they would collect data, and the sampling time frame (October 2002 to June 2003) may have been impacted by changing formularies and insurance plans during that time. Call rates may have also varied based on the time of month when data collection occurred (ie, beginning of the month versus end of the month), although previous work on diagnostic information indicates this time spread should adequately reflect seasonal variation in presenting problems. ${ }^{15}$ Third, the callback logs did not indicate type of prescribing clinician (eg, physician, physician assistant, resident) and it cannot be determined more precisely if certain clinicians were more likely to generate calls, especially residents. Fourth, although written instructions were sent and verbal instructions were given to on-site coordinators about the study protocol and definitions used on the forms, verification or monitoring did not occur to determine whether these logs represent all or nearly all the calls received from pharmacies. The outcome (callbacks) relies on the reporting accuracy and compliance of the practices, and this could have varied among practices; however, all practices were familiar with ASIPS and other PBRN studies and each site was contacted by the study coordinator and given complete instructions. Finally, pharmacists may not have identified all prescriptions that needed clarification and may have different opinions about when practices need to be called.

\section{Conclusion}

Patient safety is ensured when every step of the process, from choosing the most appropriate medication, to writing the prescription, to dispensing the medication is optimized to prevent delays in therapy and medication errors. Ultimately, it is most important that effective communication take place to ensure accurate prescriptions and optimal patient care. Although this study did not gather data on patient outcomes related to delays, pharmacy callback records serve as a useful method for identifying types of prescribing problems that should be corrected. This study represents incidents where the pharmacy has intervened to clarify prescriptions and prevent dispensing of the incorrect medication. Specifically, prescriptions for gastrointestinal, cardiovascular and analgesic/anesthetic agents should be carefully evaluated before they are given to the patient because they have been shown in this study to be the most problematic. Furthermore, prescriptions written in residencybased practices should be reviewed for accuracy and content before being given to the patient.

Reports made to the ASIPS reporting system regarding prescription issues have come from providers and staff within practices; however, a portion of these reports have been initiated by community pharmacists and patients, thus indicating that prescription and medication errors occur and are recognized throughout the entire prescription process. The ASIPS reporting system and the literature support data that pharmacists identify many potential medication errors, but it should not be expected that every adverse drug event can be caught given the volume of prescriptions and the complexity of individual patients and their health plans., ${ }^{3,16}$

Twenty-one percent $(21 \%)$ of all the callbacks in our study involved clarifications of dosages. Prescribers need to be well informed of third party prescribing policies and more aware of appropriate prescription writing. To secure patient safety throughout the process, suggested interventions include electronic prescribing systems, readily accessible and accurate medication lists, and incorporating indications for drug therapy on the prescription. With most callbacks being related to prior authorizations and formulary issues, designing a system that would accommodate automatic substitutions while meeting legal requirements for dispensing has the potential to significantly decrease the extra time needed by practices and pharmacies to clarify straightforward substitutions. Robust, clinical-based, electronic solutions could potentially remedy many of the clinical types of clarifications, but the actual impact of such remedies should be further evaluated.

\section{References}

1. Bates DW, Cullen DJ, Laird N, et al. Incidence of adverse drug events and potential adverse drug events: implications for prevention. JAMA 1995;274: 29-34.

2. Barker KN, Flynn EA, Pepper GA, Bates DW, Mikeal RL. Medication errors observed in 36 health care facilities. Arch Intern Med 2002;162:1897-903. 
3. Bond CA, Raehl CL, Franke T. Clinical pharmacy services, hospital pharmacy staffing, and medication errors in the United States hospitals. Pharmacother 2002;22:134-47.

4. Institute of Medicine. To err is human: building a safer health system. Washington (DC): National Academy Press; 1999.

5. Lesar TS, Briceland L, Stein DS. Factors related to errors in medication prescribing. JAMA 1997;277: 312-7.

6. Brennan TA, Leape LL, Laird NM, et al. Incidence of adverse events and negligence in hospitalized patients. N Engl J Med 1991;324:370-6.

7. Leape LL, Brennan TA, Laird N, et al. The nature of adverse events in hospitalized patients: results of the Harvard medical practice study II. N Engl J Med 1991;324:377-84.

8. Gandhi TK, Weingart SN, Borus J, et al. Adverse drug events in ambulatory care. N Engl J Med 2003; 348:1556-64.

9. Bedell SE, Jabbour S, Goldberg R, et al. Discrepancies in the use of medications: their extent and predictors in an outpatient practice. Arch Int Med 2000; $160: 2129-34$.
10. Medi-Span's Therapeutic Classification System. Indianapolis (IN): Medi-Span Inc.; 1998.

11. Mekhjian HS, Kumar RR, Kuehn L, et al. Immediate benefits realized following implementation of physician order entry at an academic medical center. J Am Med Inform Assoc 2002;9:529-39.

12. Kaushal R, Bates DW. Information technology and medication safety: what is the benefit?. Qual Saf Health Care 2002;11:261-5.

13. Papshev D, Peterson AM. Electronic prescribing in ambulatory practice: promises, pitfalls, and potential solutions. Am J Manag Care 2001;7:725-36.

14. Green LA, Miller RS, Reed FM, et al. How representative of typical practice are practice-based research networks? A report from the Ambulatory Sentinel Practice Network Inc (ASPN). Arch Fam Med 1993;2:939-49.

15. Pace WD, Dickinson LM, Staton EW. Seasonal variation in diagnoses and visits to family physicians. Ann Fam Med 2004;2:411-7.

16. Leape LL, Cullen DJ, Clapp MD, et al. Pharmacists' participation on physician rounds and adverse drug events in the intensive care unit. JAMA 1999;282: 267-70. 